\title{
Comparison of harmonic limits and evaluation of the international standards
}

\author{
Zijiang WANG ${ }^{1, *}$, Qionglin $\mathrm{LI}^{2}$, Yuzheng $\mathrm{TANG}^{2}$, Shuming $\mathrm{LIU}^{2}$, and Shuangyin $\mathrm{DAI}^{2}$ \\ ${ }^{1}$ Industrial Technology Research Institute of Zhengzhou University, P.R. China \\ ${ }^{2}$ State Grid Electric Power Research Institute of Henan Electric Power Company, P.R. China
}

\begin{abstract}
The paper takes the Chinese standard GB/T 14549-1993, the British Engineering Recommendation G5/4-1, the Institute of Electrical and Electronics Engineers IEEE Std 519-2014 and the part of IEC 61000-3 series standard as an example. Then summarize the difference of harmonic limits, the different processing methods of harmonic impedance, and the different summation law of each standard. Compare the harmonic limit calculation and evaluation methods of Chinese GB/T 14549-1993, British G5/4-1 and IEEE Std 519-2014 standard in detail, summarize the characteristics of the three standards in disturbance emission evaluation and introduce examples to verify the conclusion. Finally, summarize the characteristics and differences of mentioned harmonic standards.
\end{abstract}

\section{Introduction}

With the large use of power electronic switching devices, which generate non-power frequency harmonic voltages during operation [1], harmonic voltage components and resulting harmonic current in the power grid have been increasing rapidly. These harmonic currents flow into the busbars and affect the normal use and life of other powered devices connected to the busbars. Therefore, in order to minimize the impact of harmonics on the grid and customers, and to ensure the quality of power supply, countries have established harmonic limit standards according to the actual situation of the national grid and customers. Different standards use different ideas and methods. This paper compares and summarizes the difference of harmonic limits, the different processing methods of harmonic impedance, the different summation laws of Chinese standard GB/T 14549-1993, the British Engineering Recommendation G5/4-1, the American Engineers Association IEEE Std 519-2014 and the part of IEC 61000-3 series standards. Then introduce an instance to compare the calculation and evaluation methods of Chinese GB/T 14549-1993, British G5/4-1 and IEEE Std 519-2014 standard.

\section{The comparison of harmonic limits}

\footnotetext{
*Corresponding author: wzj23@126.com
} 
This part is mainly to compare the specific value of harmonic limits from different standards. At first, there is a concept of compatibility level and planning level. The compatibility level refers to the maximum level that power grid can be operated normally, above which there will be an impact. The planning level refers to the specific value set by the operator. It is the planning goal level, which ensures the stable operation of the power grid. Therefore, the planning level is generally stricter than compatibility level. Among the standards mentioned in this paper, IEC 61000-3 series standards give the indicative values of planning level but the evaluation of disturbance emission is mainly based on the compatibility level [2]. The evaluation of the other three standards is based on the planning level.

As for the THD (Total Harmonic Distortion) limits, Chinese standard GB/T 14549-1993 and British G5/4-1 are basically same. The THD limits for $35 \mathrm{kV}$ and below the grid of IEEE Std 519 is relatively loose. For $35 \mathrm{kV} \sim 69 \mathrm{kV}$ grid, IEC $61000-3$ series standards are stricter. For grid above $69 \mathrm{kV}$, IEEE Std 519 is stricter than the other three standards, except for $110 \mathrm{kV} \sim 161 \mathrm{kV}$ grid, Chinese standard GB/T 14549 is stricter.

As for the limits of harmonic voltage, IEC 61000-3 series standards and British G5/4-1 give the harmonic voltage in three categories which are odd harmonics non-multiple of 3 , odd harmonics multiple of 3 , and even harmonics. In a comparison of the two standards, the harmonic voltage limits of British G5/4-1 is stricter than IEC 61000-3 series standards under same voltage level. For the $35 \mathrm{kV} \sim 145 \mathrm{kV}$ grid, the limits of these two standards are basically the same. For a grid of higher voltage level like $275 \mathrm{kV}$ and $400 \mathrm{kV}$, the British standards stricter.

\section{Different processing methods of harmonic impedance}

The processing methods of harmonic impedance can be divided into two categories, the first is simplified method applied by Chinese standards GB/T 14549, British G5/4-1 and IEC 61000-3 series standards, which considers that the harmonic impedance is approximately equal to the harmonic order multiplied by the fundamental impedance as:

$$
Z_{h}=h Z_{1}
$$

The other method is applied by IEEE Std 519-2014. This method can bypass the direct use of harmonic impedance [3]. The concept of short-circuit ratio (SCR) is introduced in this standard, which refers to the ratio of the available short-circuit current to the load current. The harmonic current limit is translated into a relationship between the harmonic voltage limit and the SCR. The process to find harmonic impedance is bypassed. The harmonic current limit is given by the total demand distortion (TDD), which refers to the ratio of the harmonic current to the maximum demand current. It can be calculated as:

$$
\frac{I_{h}}{I_{L}}=\frac{\dot{U}_{h} \cdot U_{N}}{Z_{s h} I_{L}} \approx \frac{\dot{U}_{h} \cdot U_{N}}{h Z_{s} I_{L}}=\frac{\dot{U}_{h}}{h} \times \frac{I_{S C}}{I_{L}}=\frac{\dot{U}_{h}}{h} \times S C R
$$

In equation (2), $I_{h}$ is the harmonic current in amperes (RMS) at point of public coupling (PCC), $I_{L}$ is the maximum demand current in amperes (RMS) at PCC, $U_{h}$ is the harmonic voltage limit in per-unit value based on the rated phase voltage, $Z_{s h}$ is the harmonic impedance of order $\mathrm{h}$ at $\mathrm{PCC}, Z_{s}$ is the fundamental impedance converted from the shortcircuit capacity. As we can see from Equation (2), the harmonic current limit can be calculated directly by the SCR. Furthermore, the IEEE Std 519-2014 standard determines the harmonic current limit by assuming that the harmonic impedance is the order $h$ multiplied by the short-circuit impedance, ignoring the effects of capacitance and load. In this way, for high order harmonics, the harmonic impedance is larger so that the harmonic current limit is lower, and the margin is larger. 


\section{The comparison of summation laws}

When assessing the harmonic level in the power grid, it is necessary to consider both the background harmonics generated by the upper-level power grid to the lower-level power grid and the harmonics generated by the harmonic sources of this level. Different hypothesis are adopted when calculate the summation of different components. This part summarizes the harmonic summation laws by taking IEC 61000-3-6, British G5/4-1 and GB/T 14549-1993 standards as examples.

IEC 61000-3-6 gives a general summation law of harmonic voltage and harmonic current as [4]:

$$
U_{h}=\sqrt[\alpha]{\sum_{i} U_{h i}^{\alpha}}
$$

The summation law of harmonic current is the same as harmonic voltage. $U_{h}$ is the magnitude of the resulting harmonic voltage (order $h$ ), $U_{h i}$ is the magnitude of the various individual emission levels (order $h$ ) to be combined, $\alpha$ is an exponent as table 1 . The exponent $\alpha$ considers that the harmonic emission co-ordination mainly refers to $95 \%$ nonexceeding probability values, the aggregated global emission of different installations, the high variety of high order harmonic and so on [4].

Table 1. Summation Exponents for Harmonics (Indicative Values).

\begin{tabular}{|c|c|}
\hline Harmonic order & $\alpha$ \\
\hline $\mathrm{h}<5$ & 1 \\
$5 \leq \mathrm{h} \leq 10$ & 1.4 \\
$\mathrm{~h}>10$ & 2 \\
\hline
\end{tabular}

British G5/4-1 adopts different summation laws for different order harmonic. For harmonic order up to and including $5^{\text {th }}$, for all the triplens and for the harmonic order having the highest measured value, add the different components arithmetically as equation (4). $U_{h p}$ is summated voltage distortion, $U_{h m}$ is background harmonic value, $U_{h c}$ is the total emission from the customer's new load [5].

$$
U_{h p}=U_{h m}+U_{h c}
$$

For all other harmonics and to allow for diversity, the vector sum with $90^{\circ}$ phase angle is adopted as:

$$
U_{h p}=\sqrt{U_{h m}^{2}+U_{h c}^{2}}
$$

The summation law adopted by the Chinese standard GB / T 14549-1993 mainly uses the cosine theorem, as [6]:

$$
C_{h}^{2}=A_{h}^{2}+B_{h}^{2}+2 A_{h} B_{h} \cos \theta_{h}
$$

$\mathrm{C}_{\mathrm{h}}$ is summated value, $\mathrm{A}_{\mathrm{h}}$ is the background component from the upper-level grid, $\mathrm{B}_{\mathrm{h}}$ is the component generated in this level, $\theta_{h}$ is the phase angle of $A_{h}$ and $B_{h}$. In the actual power grid, considering the randomness of the harmonic phase and the statistical results of the power flow calculation, and the harmonic sources are generally close to each other, the summation is usually calculated as:

$$
C_{h}^{2}=A_{h}^{2}+B_{h}^{2}+A_{h} B_{h}
$$

\section{The comparison of limits calculation and disturbance emission evaluation}


This part compares the limits calculation and evaluation of GB/T 14549, British G5/4-1 and IEEE Std 519-2014 standards and introduce an example for analysis.

\subsection{Theoretical comparison of limits calculation and evaluation}

At present, most of the electrical equipment is connected to the low-voltage power grid. Therefore, the Chinese standard GB/T 14549 prioritizes the THD and the harmonic voltage limit of the low-voltage power grid. Then the limits of the other voltage levels are based on this. So that most of the electrical equipment can be ensured to operate normally. Considering the influence of stator winding heating on the life of AC induction motor, the influence of capacitor overvoltage and overcurrent on its life, and the influence of harmonic distortion on the computer, the Chinese standard GB/T 14549 determines that the THD limit of the $0.38 \mathrm{kV}$ grid is $5 \%$. Then, according to the transmission relationship between the different voltage levels, the THD limits of other voltage levels are determined as shown in table 2.

Table 2. Harmonic Voltage Limits of Power System of GB/T 14549-1993.

\begin{tabular}{|c|c|c|c|}
\hline \multirow{2}{*}{ Voltage Level/kV } & \multirow{2}{*}{ THD/\% } & \multicolumn{2}{|c|}{ Harmonic Voltage/\% } \\
\cline { 3 - 4 } & & Odd Order & Even Order \\
\hline 0.38 & 5.0 & 4.0 & 2.0 \\
\hline 6,10 & 4.0 & 3.2 & 1.6 \\
\hline 35,66 & 3.0 & 2.4 & 1.2 \\
\hline 110 & 2.0 & 1.6 & 0.8 \\
\hline
\end{tabular}

Since the actual measurement results show that the harmonic of phase voltage is higher than the line voltage, the harmonic voltage limit calculation is based on the phase voltage. The harmonic voltage limits of table 2 are the result after the summation of background component from the upper-level grid and the component generated in this level. equation (7) can be transferred into equation (8) to calculate the harmonic voltage limits of harmonic sources in each voltage level.

$$
B_{h}=\sqrt{C_{h}^{2}-0.75 A_{h}^{2}}-0.5 A_{h}
$$

Taking the influence of network component impedance such as transformers and resonance amplification into account, the transmission coefficient of the Chinese standard $\mathrm{GB} / \mathrm{T}$ 14549-1993 to transfer harmonic voltage from the upper-level grid to the lower-level grid is 0.8 . At the same time, for the harmonic components transferred to $110 \mathrm{kV}$ grid from $220 \mathrm{kV}$ grid, THD is approximately $0.8 \%$, odd harmonic voltage is approximately $0.6 \%$, even harmonic voltage is approximately $0.3 \%$. Then we can get the harmonic voltage limits of harmonic sources in each voltage level as table 3.

Table 3. Harmonic Voltage Limits of Harmonic Sources in Different Levels of GB/T 14549-1993.

\begin{tabular}{|c|c|c|c|}
\hline \multirow{2}{*}{ Voltage Level/kV } & \multirow{2}{*}{ THD/\% } & \multicolumn{2}{|c|}{ Harmonic Voltage/\% } \\
\cline { 3 - 4 } & & Odd Order & Even Order \\
\hline 0.38 & 2.6 & 2.0 & 1.0 \\
\hline 6,10 & 2.2 & 1.8 & 0.9 \\
\hline 35,66 & 1.9 & 1.5 & 0.7 \\
\hline 110 & 1.5 & 1.2 & 0.6 \\
\hline
\end{tabular}


Equation (1) can be calculated as:

$$
Z_{h}=h \frac{\left(1000 U_{N}\right)^{2}}{10^{6} S_{k}}=\frac{h U_{N}^{2}}{S_{k}}
$$

$\mathrm{S}_{\mathrm{k}}$ is the reference short-circuit capacity in MVA, $\mathrm{U}_{\mathrm{N}}$ is the nominal voltage of the grid in $\mathrm{kV}$. The $\mathrm{h}$ order harmonic voltage $\left(\mathrm{HRU}_{\mathrm{h}} \%\right)$ can be calculated as:

$$
H R U_{h}=\frac{U_{h}}{U_{1}} \times 100 \%=\frac{I_{h} Z_{h}}{1000 U_{N} / \sqrt{3}} \times 100 \%=\frac{\sqrt{3} I_{h} Z_{h}}{10 U_{N}} \%
$$

Combine equation (9) and equation (10), we can get:

$$
I_{h}=\frac{10 S_{k} \cdot H R U_{h}}{\sqrt{3} U_{N} \cdot h}
$$

According to the equation (11) and table 3, the total harmonic voltage limits of each voltage level grid can be calculated. Then we can get the harmonic voltage limits for each customer as [6]:

$$
I_{h i}=I_{h}\left(S_{i} / S_{t}\right)^{1 / \alpha}
$$

$\mathrm{S}_{\mathrm{i}}$ is the capacity of the customer $\mathrm{i}, \mathrm{S}_{\mathrm{t}}$ is the sum of the capacity allocations of all installations at PCC, $\alpha$ is Phase Superposition Coefficient as table 4.

Table 4. The Value of Phase Superposition Coefficient $\alpha$.

\begin{tabular}{|c|c|c|c|c|c|c|}
\hline $\mathrm{h}$ & 3 & 5 & 7 & 11 & 13 & $9,>13$, Even Order \\
\hline$\alpha$ & 1.1 & 1.2 & 1.4 & 1.8 & 1.9 & 2.0 \\
\hline
\end{tabular}

When the actual short-circuit capacity $S_{\mathrm{ki}}$ isn't totally the same as the reference shortcircuit capacity $S_{\mathrm{k}}$, the harmonic current limits can be transferred as [6]:

$$
I_{h}{ }^{\prime}=I_{h} \cdot S_{k}{ }^{\prime} / S_{k}
$$

The evaluation process is divided into three stages in the British G5/4-1 standard. Stage 1 is simplified evaluation for the $230 / 400 \mathrm{~V}$ grid. When the connections of equipment comply with the relevant limits and other conditions, they can be connected to the grid. Stage 2 and stage 3 are the core of the evaluation process. The idea of evaluation is different with Chinese standard GB/T 14549. Chinese standard requests customer to inform the capacity they need before the limits are given. But in British standard, connections of customer's equipment which comply with emission limits may be without a voltage evaluation provided that the levels of network distortion are less than $75 \%$ of the planning levels. If the connections don't comply with the emission limits, further harmonic voltage prediction calculations of equation (4) and (5) are needed. Different from the idea that the Chinese standard calculates the harmonic limit of each customer according to the customer's capacity and the total limit, G5/4-1 summates the customer's harmonic voltage with the background harmonic voltage and compares it with the overall limit. The specific calculation method can be transformed roughly from equation (11). What is different is that the British G5/4-1 considers the harmonics generated by the low-order parallel resonance that may occur in this frequency range, introducing the empirical coefficient $\mathrm{k}$ as:

$$
H R U_{h}=\frac{I_{h} k h \sqrt{3} U_{N}}{10 S_{k}} \%
$$

For the $400 \mathrm{~V}$ grid, $\mathrm{k}$ is 1 when $\mathrm{h} \leq 7, \mathrm{k}$ is 0.5 when $\mathrm{h}>7$. For $6.6 \mathrm{kV}, 11 \mathrm{kV}, 20 \mathrm{kV}$ and $22 \mathrm{kV}$ grid, $\mathrm{k}$ is 2 when $\mathrm{h} \leq 8, \mathrm{k}$ is 1 when $\mathrm{h}>8$.

In comparison with the limits of the Chinese standard and the British G5/4-1, the Chinese standard is relatively stricter. The total harmonic planning limits are divided according to the customer's capacity in Chinese standard GB/T 14549-1993. So that there 
will be a lot of margins when customers control their emission equal to or below the limits. But it might be difficult for new customers when connecting to the grid if they don't inform the system operator before the limits are set. The main advantage of the British G5/4-1 is its flexibility. There are no certain harmonic limits for customers to connect to the grid. It can be adjusted according to the actual situation of the grid and the needs of customers. The disadvantage is also obvious that there will be more emission space for earlier connection but nearly no more space for later connection. It is not fair for customers who connect to the grid later.

The IEEE Std 519-2014 simplifies the harmonic voltage limits and THD limits only for different voltage levels [6]. However, the harmonic current limits of IEEE Std 519-2014 are more detailed. In different voltage levels, the standard firstly calculates the ratio of the short-circuits current to the maximum demand current to get SCR of customers. Then calculate the TDD of customers using equation (2) and compare the TDD with the limit according to the different interval of SCR. The main advantage to use TDD as the harmonic current limit is that it can prevent that in some cases the THD value is large but the actual amplitude of the harmonic current is small. Because sometimes little amplitude of harmonic current may account for a large proportion in which case will not impact the power system.

\subsection{Comparative analysis of examples}

Taking the Guangzhou and Zhuhai Electrified Railway Guanyao Traction Station as an example, according to the PSCAD/EMTDC simulation results, it is analyzed whether it complies with the limits of three harmonic standards in section 5.1. The Guangzhou and Zhuhai Railway Guanyao Traction Station uses a $110 \mathrm{kV} / 27.5 \mathrm{kV}$ three-phase V/V wiring transformer with an impedance voltage of $8.4 \%$ and with twice the overload capacity. The recent $95 \%$ probability maximum load of the Guanyao Traction Station is 26454kVA. Considering the situation of the power grid near the Guanyao Traction Station and the power supply capacity of the $220 \mathrm{kV}$ transformer, the power station that can be considered near the Guanyao Traction Station are 110kV Taobu Station and 110kV Leping Station. Next, the harmonic levels of the two power supply schemes are analyzed and evaluated. The THD results of Taobu Station and Leping Station obtained from the simulation results are shown in table 5 .

Table 5. The THD of PCC of Guanyao Traction Station and THD Limits.

\begin{tabular}{|c|c|c|c|c|c|}
\hline \multirow{2}{*}{ Power Station } & \multicolumn{3}{|c|}{ THD (\%) } & \multirow{2}{*}{$\begin{array}{c}\text { GB/T 14549 } \\
\text { THD Limits (\%) }\end{array}$} & $\begin{array}{c}\text { G5/4-1 and IEEE Std 519 } \\
\text { THD Limits (\%) }\end{array}$ \\
\cline { 2 - 4 } & Phase A & Phase B & Phase C & THD & \multirow{2}{*}{2.5} \\
\hline Taobu & 0.512 & 1.008 & 0.496 & 2 & 2.527 \\
\hline Leping & 0.546 & 1.074 & 0.527 & \\
\hline
\end{tabular}

It is shown from table 5 that the THD of the two power supply schemes of the Guanyao Station does not exceed the three standards' limits. According to the simulation results, the harmonic current can be obtained as shown in table 6 .

Table 6. The Harmonic Current of Guanyao Traction Station (A).

\begin{tabular}{|c|c|c|c|c|c|c|c|c|c|}
\hline \multirow{2}{*}{$\begin{array}{c}\text { Power } \\
\text { Station }\end{array}$} & \multicolumn{3}{|c|}{ 3rd Harmonic Current } & \multicolumn{3}{c|}{ 5th Harmonic Current } & \multicolumn{3}{c|}{ 7th Harmonic Current } \\
\cline { 2 - 10 } & Phase A & Phase B & Phase C & Phase A & Phase B & Phase C & Phase A & Phase B & Phase C \\
\hline Taobu & 8.380 & 16.446 & 8.066 & 5.116 & 10.064 & 4.948 & 5.041 & 9.914 & 4.873 \\
\hline Leping & 7.854 & 15.410 & 7.546 & 5.009 & 9.851 & 7.082 & 4.952 & 9.737 & 4.785 \\
\hline
\end{tabular}


The capacity data of PCC is shown in table 7. The short-circuit capacity of the $110 \mathrm{kV}$ busbar of the Taobu Station is 2050MVA, and the short-circuit capacity of the $110 \mathrm{kV}$ busbar of Leping Station is 1804MVA.

Table 7. The Capacity of Power Station Connected to the PCC of $110 \mathrm{kV}$ Grid.

\begin{tabular}{|c|c|c|c|c|c|c|}
\hline Power Station & Taobu & Leping & Longkou & Beiqu & Gulao & Sancun \\
\hline Capacity (MVA) & $2 * 63$ & $2 * 50$ & 40 & $2 * 40$ & $31.5+40$ & $2 * 50$ \\
\hline
\end{tabular}

\subsubsection{The evaluation according to Chinese standard GB/T 14549-1993}

The odd harmonic voltage limit of the $110 \mathrm{kV}$ grid of Chinese standard is $1.6 \%$, the even harmonic voltage limit is $0.8 \%$. Combined with data in Table 5 , some of them are above the limit. The harmonic current limits of the $110 \mathrm{kV}$ grid PCC of Chinese standard are shown as table 8 .

Table 8. The Harmonic Current Limits of PCC of GB/T 14549.

\begin{tabular}{|c|c|c|c|c|}
\hline \multirow{2}{*}{ Voltage Level (kV) } & \multirow{2}{*}{$\begin{array}{c}\text { Reference Short-Circuit } \\
\text { Capacity (MVA) }\end{array}$} & \multicolumn{3}{|c|}{ The Harmonic Order and Limits (A) } \\
\cline { 3 - 5 } & 750 & 3 & 5 & 7 \\
\hline 110 & 9.6 & 9.6 & 6.8 \\
\hline
\end{tabular}

According to equation (13) and table 8, the PCC harmonic current limits of Guanyao Traction Station can be calculated as:

Table 9. The PCC Harmonic Current Limits of Guanyao Traction Station (A) of GB/T 14549.

\begin{tabular}{|c|c|c|c|}
\hline Power Station & $\begin{array}{c}\text { 3rd Harmonic Current } \\
\text { Limit }\end{array}$ & $\begin{array}{c}\text { 5th Harmonic Current } \\
\text { Limit }\end{array}$ & $\begin{array}{c}\text { 7th Harmonic Current } \\
\text { Limit }\end{array}$ \\
\hline Taobu & 26.24 & 26.24 & 18.59 \\
\hline Leping & 23.09 & 23.09 & 16.36 \\
\hline
\end{tabular}

According to the data of table 9 and table 7, the harmonic current limits of the single customer can be calculated by equation (12) and table 4 as:

Table 10. The Harmonic Current Limits of Single Customer of GB/T 14549.

\begin{tabular}{|c|c|c|c|}
\hline Power Station & $\begin{array}{c}\text { 3rd Harmonic Current } \\
\text { Limit }\end{array}$ & $\begin{array}{c}\text { 5th Harmonic Current } \\
\text { Limit }\end{array}$ & $\begin{array}{c}\text { 7th Harmonic Current } \\
\text { Limit }\end{array}$ \\
\hline Taobu & 7.264 & 8.085 & 6.777 \\
\hline Leping & 5.181 & 5.868 & 5.056 \\
\hline
\end{tabular}

By comparing the data of table 6 and table 10, according to the Chinese standard GB/T 14549 limit, there are situations that the two power supply schemes' harmonic current exceeds the limits.

\subsubsection{The evaluation according to british G5/4-1}

According to British G5/4-1, with the data of table 6 and equation (14), the harmonic voltage generated by the harmonic source in the $110 \mathrm{kV}$ voltage level can be calculated as: 
Table 11. The Harmonic Voltage Generated by Harmonic Source in 110kV voltage level of G5/4-1.

\begin{tabular}{|c|c|c|c|c|c|c|c|c|c|}
\hline \multirow{2}{*}{$\begin{array}{c}\text { Power } \\
\text { Station }\end{array}$} & \multicolumn{3}{|c|}{$\begin{array}{c}\text { 3rd Harmonic Voltage } \\
\text { Limit\% }\end{array}$} & \multicolumn{3}{c|}{$\begin{array}{c}\text { 5th Harmonic Voltage } \\
\text { Limit\% }\end{array}$} & \multicolumn{3}{c|}{ 7th Harmonic Voltage Limit\% } \\
\cline { 2 - 10 } & Phase A & Phase B & Phase C & Phase A & Phase B & Phase C & Phase A & Phase B & Phase C \\
\hline Taobu & 0.639 & 1.253 & 0.615 & 0.650 & 1.278 & 0.628 & 0.896 & 1.763 & 0.867 \\
\hline Leping & 0.599 & 1.174 & 0.575 & 0.636 & 1.251 & 0.899 & 0.881 & 1.732 & 0.851 \\
\hline
\end{tabular}

Assume that the background THD of the $110 \mathrm{kV}$ grid is $0.8 \%$, and the background odd harmonic voltage is $0.6 \%$. According to the summation law given in British G5/4-1, as shown in equation (4) and equation (5), summate the data of Table 11 with the background harmonic. Then the summated harmonic voltage is table 12:

Table 12. The Harmonic Voltage of $110 \mathrm{kV}$ Grid of G5/4-1.

\begin{tabular}{|c|c|c|c|c|c|c|c|c|c|}
\hline \multirow[t]{2}{*}{ Power Station } & \multicolumn{3}{|c|}{$\begin{array}{c}\text { 3rd Harmonic Voltage } \\
\text { Limit } \%\end{array}$} & \multicolumn{3}{|c|}{$\begin{array}{c}\text { 5th Harmonic Voltage } \\
\text { Limit } \%\end{array}$} & \multicolumn{3}{|c|}{$\begin{array}{c}\text { 7th Harmonic Voltage } \\
\text { Limit } \%\end{array}$} \\
\hline & Phase A & Phase B & Phase C & Phase A & Phase B & Phase C & Phase A & Phase B & Phase C \\
\hline Taobu & 1.239 & 1.853 & 1.215 & 1.250 & 1.878 & 1.228 & 1.079 & 1.862 & 1.054 \\
\hline Leping & 1.199 & 1.774 & 1.175 & 1.236 & 1.851 & 1.499 & 1.066 & 1.833 & 1.041 \\
\hline
\end{tabular}

The British G5/4-1 standard stipulates that for the $20 \mathrm{kV} \sim 145 \mathrm{kV}$ grid, the harmonic voltage limit of $3 \mathrm{rd}, 5$ th, 7 th harmonic is $2 \%$. It can be seen from the data in table 11 that the harmonic voltage of the Taobu and Leping station meet the requirements of G5/4-1.

\subsubsection{The evaluation according to IEEE Std 519-2014}

According to the SCR method mentioned in Section 3, Taobu Station can be used as an example to get the SCR as:

$$
S C R=\frac{I_{S C}}{I_{L}}=\frac{S_{S C} / \sqrt{3} U_{N}}{S_{L} / \sqrt{3} U_{N}}=\frac{2050 \times 1000 / 110 \sqrt{3}}{26454 / 110 \sqrt{3}}=77.493
$$

The SCR of Taobu Station ranges from 50 to 100. According to the limit of IEEE Std $519-2014$, for the grid between $69 \mathrm{kV}$ and $161 \mathrm{kV}$, the ratio of the $3 \mathrm{rd}$ to 10 th harmonic currents must not exceed 5\%, calculate its specific harmonic current limit as:

$$
I_{h}=I_{L} \times 5 \%=\frac{26454}{110 \sqrt{3}} \times 5 \%=6.9425 \mathrm{~A}
$$

The harmonic current can be obtained as table 13:

Table 13. The Harmonic Current Limits of Single Customer of IEEE Std 519-2014.

\begin{tabular}{|c|c|c|c|}
\hline Power Station & $\begin{array}{c}\text { 3rd Harmonic } \\
\text { Current Limit }\end{array}$ & $\begin{array}{c}\text { 5th Harmonic } \\
\text { Current Limit }\end{array}$ & $\begin{array}{c}\text { 7th Harmonic Current } \\
\text { Limit }\end{array}$ \\
\hline Taobu & 6.9425 & 6.9425 & 6.9425 \\
\hline Leping & 6.9425 & 6.9425 & 6.9425 \\
\hline
\end{tabular}

In comparison with table 6 and table 13, there are harmonic currents which exceed the limits of IEEE Std 519-2014. 


\subsubsection{Comparison of evaluation results}

After the evaluation of three standards for two power supply schemes of Guanyao Traction Station, it can be seen that these two schemes only meet the limits of British G5/4-1 standard. From the analysis of this example, the limits of the Chinese standard GB/T 14549 are directly dependent on the customer's capacity, and the limits for the small-capacity customer are stricter. The limits of IEEE Std 519 are not directly dependent on the customer's capacity but is determined by the SCR interval [7]. The limits are the same if the SCR of different customers is in the same interval. The British G5/4-1 standard is relatively more flexible. The limits of G5/4-1 are depended by the background harmonic level. In this paper, under the circumstance of an average background harmonic level, G5/4-1 allows more harmonic emission than the other two standards.

\section{Summary}

Overall, the concept and evaluation method of the IEC 61000-3 series standards is the basis for other standards [8]. IEC 61000-3 series standards focus on discussing the EMC compatibility of grid [4],[9]-[11]. IEEE Std 519-2014 offers a new method which introduces SCR to solve the difficulties that harmonic impedance is hard to estimate. So that it is much easier to calculate the limits of harmonic current. At the same time, IEEE Std 519-2014 uses TDD for the harmonic current limits, which can avoid the situation that small harmonic current causes high THD. British G5/4-1 standard is based on the IEC 61000-3 series standards, but the limits are relatively higher. And G5/4-1 takes the operation of the actual power grid into account. It is more flexible for distortion sources to connect to the grid. Especially for customers with large capacity, it will be much easier for them to connect to the grid. Chinese standard GB/T $14549-1993$ is relatively strict. It divides the total harmonic voltage limits of the whole grid into several parts according to the capacity of each customer and distributes the limit to every customer. So the total harmonic level will not exceed the total level of the whole grid, but it is not flexible for new customers when connecting to the grid.

\section{References}

1. Haixue LIN Introduction to the Foreign Standards of Harmonic Current Limits Distribution \& Utilization 2008(05):1-8

2. Qing MO, Haoliang SUN Basis and Derivation of Harmonic Current Limits in IEC Standards for Power Equipments Power System Technology 2000(04):67-70

3. Haixue LIN Introducing Current Limits in US Harmonic Standard IEEE Std. 519 Distribution \& Utilization 2012,29(05):11-14

4. Electromagnetic compatibility (EMC) - Part 3-6: Limits -- Assessment of emission limits for the connection of distorting installations to MV, HV and EHV power systems (IEC 61000-3-6:2008)

5. Engineering Recommendation G5/4-1, Planning Levels For Harmonic Voltage Distortion And The Connection Of Non-Linear Equipment To Transmission Systems And Distribution Networks in The United Kingdom, Issue 4 Amendment 1-October 2005.

6. Chinese Standards, Quality of electric energy supply Harmonic in public supply network (GB/T 14549-1993) 
7. IEEE Recommended Practice and Requirements for Harmonic Control in Electric Power Systems (IEEE Std 519-2014)

8. Haixue LIN On Difference Between National Standard and IEC 61000 Standards of EMC in Harmonic Power System Technology 1999(05):64-67

9. Electromagnetic compatibility (EMC) - Part 3-2: Limits - Limits for harmonic current emissions (equipment input current $\leq 16$ A per phase) (IEC 61000-3-2:2014)

10. Electromagnetic compatibility (EMC) - Part 3-12: Limits - Limits for harmonic currents produced by equipment connected to public low-voltage systems with input current $>16 \mathrm{~A}$ and $\leq 75$ A per phase (IEC 61000-3-12:2011)

11. Electromagnetic compatibility (EMC) - Part 3-4: Limits - Limitation of emission of harmonic currents in low-voltage power supply systems for equipment with rated current greater than 16 A (IEC 61000-3-4:1998) 